\title{
MYCOLOGY
}

\section{In-situ detection of Aspergillus fumigatus}

\author{
RYO HANAZAWA*, SOMAY YAMAGATA MURAYAMA* and HIDEYO YAMAGUCHI*†
}

*Department of Microbiology and Immunology, Teikyo University School of Medicine, 2-11-1, Kaga, ItabashiKu, Tokyo 173-8605 and †Teikyo University Institute of Medical Mycology, 359, Otsuka, Hachioji, Tokyo 1920395, Japan

An in-situ hybridisation (ISH) technique to detect Aspergillus fumigatus in infected tissues was developed in which 568-bp, 333-bp and 154-bp PCR products of the alkaline proteinase gene were employed. Dot-blot hybridisation with the 568-bp probe on a membrane containing genomic DNA from several different fungi including A. flavus, A. niger, Penicillium spp., Mucor racemosus or Pseudallescheria boydii gave negative results. ISH was done on formalin-fixed, paraffin-embedded pulmonary tissues from rats infected with $A$. fumigatus and renal tissues from mice infected with $A$. fumigatus, $A$. flavus or A. niger. The 568-bp probe reacted strongly in ISH with both A. fumigatus and A. flavus, and weakly with A. niger. The 333-bp probe also reacted in ISH with A. fumigatus and A. flavus, although the intensity was weaker. However, in ISH with the 154-bp probe, there was no positive signal with any Aspergillus spp. These results demonstrate that $A$. fumigatus and $A$. flavus can be specifically detected in infected tissues by ISH with the 568-bp probe. This technique could be applicable to clinical specimens for molecular diagnosis of aspergillus infections.

\section{Introduction}

Invasive aspergillosis caused by pathogenic Aspergillus species is a serious hazard for immunocompromised patients and the number of patients whose immune systems are compromised by either congenital or acquired immune deficiency states has increased recently [1]. The diagnosis of systemic fungal infections is a major challenge because their clinical presentation is usually non-specific. Clinical diagnosis of invasive aspergillosis is difficult and is largely presumptive, typically based on the presence of a spiking fever that does not respond to antibiotics in a patient with the known risk factors. The clinical samples most often available for microbiological diagnosis are sputum, bronchial washings and bronchoalveolar lavage (BAL) fluids. However, diagnosis by culture, PAS stain and immunohistochemical staining is difficult; moreover, culture of Aspergillus spp. is not proof of infection. Serological tests for the detection of antibodies are less helpful because of the poor antibody responses in immunosuppressed patients and methods currently used for detecting circulating aspergillus antigens, such as latex agglutination tests and ELISA

Received 23 Feb. 1999; revised version accepted 8 Aug. 1999; accepted 16 Aug. 1999.

Corresponding author: Dr R. Hanazawa (e-mail: rhanazaw@ med.teikyo-u.ac.jp). for galactomannan, have poor sensitivity and specificity and can produce false-positive results [2,3].

With the development of molecular biological techniques, it is now possible to detect and identify various pathogens. The PCR technique has been shown to be a more sensitive diagnostic method for aspergillus infections [4]. Although it is highly sensitive and can be performed within a short period, the result is sometimes doubtful because sputum or BAL specimens are not suitable for PCR. Therefore, the most reliable evidence is derived from mycological or histological proof of tissue invasion, which is often difficult to obtain. Direct histological detection of the fungus in biopsy material from invaded tissues may offer the best diagnostic evidence, provided that the fungal species involved is correctly identified. However, the specificity of histopathological or immunological detection methods currently available is not satisfactory. In-situ hybridisation (ISH) shows promise for the diagnosis of fungal pathogens in infected tissues. ISH can also provide simultaneous information on the localisation of pathogens in the tissue or cells. There are numerous reports describing ISH techniques for detection of several pathogenic bacteria, chlamydia and protozoa, such as Staphylococcus aureus [5], Chlamydia trachomatis [6] and Trichomonas vaginalis [7]. To detect a virus such as the human immunodeficiency virus type 1 (HIV-1) [8], an ISH technique combined with PCR has 
been used to increase sensitivity. Although ISH is beginning to attract attention as a new method for the detection and diagnosis of pathogenic organisms in situ, only two laboratories have reported their application to pathogenic fungi: one for Aspergillus spp. $[9,10]$ and the other for Pneumocystis carinii [11]. These reports dealt with ISH techniques to detect specific RNA of the pathogenic fungi.

Most investigators who have studied ISH methods for bacteria or fungi have chosen specific RNA as the target because it is present in high copy number in individual cells [10]. However, as RNA is immediately degradable, it is difficult to apply this approach to clinical specimens in the routine clinical laboratory. If DNA was chosen as an alternative target, ISH procedures would be much easier. For these reasons, the present study attempted to develop an ISH technique to detect fungus-specific DNA with the alkaline proteinase (ALP) gene of $A$. fumigatus, which is known to be one of the major virulence factors of this medically important fungus [12].

\section{$M$ aterials and methods}

\section{Probes}

The ALP sequence of $A$. fumigatus was extracted from the DDBJ database and after comparing homology with other fungal ALP genes by the DDBJ FASTA program, $568 \mathrm{bp}$ of the sequence highly specific to $A$. fumigatus ALP were selected. To study the effect of probe length on hybridisation signals, shorter probes were designed. The alp-568, alp-333 and alp-154 probes were 568 bp, $333 \mathrm{bp}$ and $154 \mathrm{bp}$ length PCR products, respectively, amplified from the ALP gene in $A$. fumigatus TIMM 0063. The alp-568 probe was synthesised by PCR with a specific primer pair, alp-s (5'-tccgtgtactt gatgggtct-3': 20 mer) and alp-r (5'-ggcactccttacaactag ca-3': 20 mer). The alp-333 probe (333 bp: the upper was alp-1798s 5'-cctgaatctatgagccctac-3' 20 mer, and the lower alp-r) was an internal probe of the alp-568 probe. The alp-154 probe (154 bp: the upper was alp1977s 5'-acctccactgtcttcgcta-3' 20 mer, the lower was alp-r) was an internal probe of the alp-333 probe.

All probes were digoxigenin (DIG)-labelled when PCR was performed. DIG-labelling and synthesis of each probe were as follows: $10 \mu \mathrm{l}$ of $10 \times \mathrm{PCR}$ reaction buffer (100 mM Tris- $\mathrm{HCl}, \mathrm{pH} 8.3,500 \mathrm{~mm} \mathrm{KCl}, 15 \mathrm{~mm}$ $\left.\mathrm{MgCl}_{2}\right), \quad 100 \mu \mathrm{M}$ dNTP and $5 \mu \mathrm{M}$ DIG-11-dUTP (Roche Diagnostics, USA), $100 \mathrm{pmol}$ of primer alp-s, alp-1789s, alp-1977s or alp-r, $100 \mathrm{ng}$ of template DNA extracted from A. fumigatus TIM M 0063 and 2.5 units of Taq DNA polymerase (Takarashuzo, Shiga, Japan) were mixed together in a final volume of $100 \mu$ made up with distilled water. The reaction mixture was subjected to thermal cycling of $94^{\circ} \mathrm{C}$ for 5 min for 1 cycle, $94^{\circ} \mathrm{C}$ for $1 \mathrm{~min}, 57^{\circ} \mathrm{C}$ for $2 \mathrm{~min}$ and $72^{\circ} \mathrm{C}$ for 3 min for 30 cycles, followed by a final incubation at $72^{\circ} \mathrm{C}$ for $10 \mathrm{~min}$ in a DNA thermal cycler (Perkin Elmer Cetus, USA). A Mycoplasma-specific probe (646 bp) [13] which was part of the ITS gene was used as a negative control. The PCR products were analysed by electrophoresis on an agarose $1.2 \%$ gel. Labelling efficiency of the alp probes was confirmed by dotblotting with a nylon membrane filter (Hybond- $\mathrm{N}^{+}$: A mersham pharmacia biotech, Buckinghamshire). Two $\mu l$ of each sequentially diluted (1:1 to $1: 3125)$ probe were blotted on a nylon membrane filter. Signals were detected as in the ISH methods. Those probes that gave positive results at 625 to 3125 -fold dilutions were selected for ISH.

\section{Preparation of tissue specimens from infected animals}

Female rats (Sprague-Dawley, Charles River Japan, K anagawa, Japan) $220-250 \mathrm{~g}$ in weight, were immunosuppressed with cyclophosphamide (CY; Shionogi \& Co., Ltd, Osaka, Japan) $25 \mathrm{mg} / \mathrm{kg}$ and prednisolone (M itaka Pharmaceutics, Tokyo, Japan) $25 \mathrm{mg} / \mathrm{kg}$ injected subcutaneously on days $-7,-5,-3,-1,1,3,5$ and 10. A garose beads $(100 \mu \mathrm{l})$ containing $4 \times 10^{4} \mathrm{~A}$. fumigatus TIMM 0063 spores $/ \mathrm{ml}$ were gently injected into a catheter which was introduced through the small cervical incision exposing the trachea and advanced to the left main bronchus on day 0 . Pulmonary tissues were taken after 13 days [14]. For studies with mice, $150 \mathrm{mg} / \mathrm{kg}$ of $\mathrm{CY}$ were administered intraperitoneally to each 4-week-old mouse (SPF ICR, Charles River Japan) 6,3 and 0 days before intravenous injection of $3 \times 10^{7}$ spores of $A$. fumigatus TIM M 0063, A. flavus TIMM 2935, A. niger TIMM 2932 or Trichosporon asahi TIMM 3144. The renal tissues were taken after 7 days, fixed in buffered formalin $10 \%$ and embedded in paraffin. Tissue sections (5-6 $\mu \mathrm{m}$ thick) were mounted on aminoalkylsilane-coated slides (Daco Japan, Tokyo, Japan).

\section{In-situ hybridisation}

Tissue sections mounted as above were dewaxed with xylene and rehydrated through an ethanol series (100$70 \%$ ). After washing with distilled water, the tissue sections were treated with $0.2 \mathrm{~N} \mathrm{HCl}$ for $10 \mathrm{~min}$ at room temperature, washed with distilled water and then digested with proteinase K (Merck, Darmstadt, Germany) $2 \mu \mathrm{g} / \mathrm{ml}$ in distilled water at $37^{\circ} \mathrm{C}$ for $5 \mathrm{~min}$. To inactivate proteinase $\mathrm{K}$, the tissue sections were washed with TE buffer ( $10 \mathrm{~mm}$ Tris- $\mathrm{HCl}, \mathrm{pH} 7.5,1 \mathrm{~mm}$ EDTA) and heated at $94^{\circ} \mathrm{C}$ for 5 min on a DNA thermal cycler. They were kept for $5 \mathrm{~min}$ at room temperature and then dehydrated in an ethanol series (70-100\%) and airdried. Finally, the tissue sections were covered with $100 \mu \mathrm{l}$ of hybridisation buffer $(10 \mathrm{~mm}$ Tris- $\mathrm{HCl}, \mathrm{pH}$ 7.6, formamide $50 \%$, Denhart's solution, dextran sulphate $10 \%, 600 \mathrm{mM} \mathrm{NaCl}$, SDS $0.25 \%, 1 \mathrm{~mm}$ EDTA, pH 8.0) and heated at $94^{\circ} \mathrm{C}$ for $10 \mathrm{~min}$ on a DNA thermal cycler. They were immediately cooled on 
ice. Prehybridisation was performed at $50^{\circ} \mathrm{C}$ for $1 \mathrm{~h}$ in the presence of formamide $50 \%$.

The DIG-labelled probes were heated in boiling water for $10 \mathrm{~min}$ and then cooled in ice water immediately; $100 \mu \mathrm{l}$ of the hybridisation buffer containing four denatured probes $(2 \%, 5 \%, 10 \%, 20 \%)$ was applied to the tissue sections and covered with Parafilm ${ }^{\circledR}$ (A merican National $\operatorname{Can}^{\top \mathrm{M}}$, USA). Hybridisation was performed overnight at $50^{\circ} \mathrm{C}$ in a moist chamber in the presence of formamide $50 \%$.

After hybridisation, the tissue sections were washed twice in $2 \times \mathrm{SSC}(0.03 \mathrm{M} \mathrm{NaCl}, 0.03 \mathrm{M}$ sodium citrate) at $50-55^{\circ} \mathrm{C}$ for $15 \mathrm{~min}$ and successively in $0.2 \times \mathrm{SSC}$ in the same way to remove unhybridised and mismatched probes, dipped in buffer 1 ( $0.1 \mathrm{M}$ maleic acid, $0.15 \mathrm{M} \mathrm{NaCl}, \mathrm{pH} 7.5)$ and blocked with blocking reagent (Roche Diagnostics, USA) $10 \% \mathrm{v} / \mathrm{v}$ in buffer 1 at room temperature for $1 \mathrm{~h}$. The DIG-labelled hybridisation products were detected with anti-DIGalkaline phosphatase conjugates (Roche Diagnostics). An anti-DIG agent (diluted 500-fold with buffer 1) was applied to the tissue sections and allowed to react at room temperature for $30 \mathrm{~min}$. A ny extra anti-DIG agent was removed by washing three times in buffer 1 containing Tween $200.2 \%$ for $15 \mathrm{~min}$ and then rinsed with buffer $3(0.1 \mathrm{M}$ Tris $-\mathrm{HCl}, \mathrm{pH} 9.5,0.1 \mathrm{M} \mathrm{NaCl}$, $0.1 \mathrm{M} \mathrm{M} \mathrm{gCl}_{2}$ ). To visualise the signals, the colour was developed in the tissue sections with nitroblue tetrazolium salt (NBT; Roche Diagnostics) and 5-bromo-4chlor-3indolylphosphate (BCIP; Roche Diagnostics) as substrates for alkaline phosphatase at $37^{\circ} \mathrm{C}$ overnight in a shading box and immediately rinsed with buffer 4 (10 mM Tris- $\mathrm{HCl}, \mathrm{pH} 8.0,1 \mathrm{~mm}$ EDTA) to stop the reaction. The stained hybridisation slide was dried and mounted with a coverglass for observation by light microscopy.

As negative controls, ISH procedures with the Mycoplasma-specific probe or uninfected lung or kidney tissues of mice infected with $T$. asahi were performed in the same experimental conditions. Control tests were also performed: (1) ISH with the unlabelled alp-568 probe and (2) ISH of competitive inhibition with unlabelled and labelled probes.

\section{Confirmation of probe specificity}

Specificity of the alp-probe group was confirmed by dot-blot hybridisation on a nylon membrane filter (Hybond- $\mathrm{N}^{+}$: A mersham International, Little Chalfont, Buckinghamshire). DNA was extracted from the following fungal strains: A. fumigatus TIM M 0063, A. fumigatus TIM M 1776, A. flavus TIM M 2935, A. niger TIMM 2932, Penicillium expansum TIMM 1293, P. citreo-viride TIMM0082, P. citrinum TIMM 1330, P. crustosum TIM M 1332, M ucor racemosus TIM M 1321 and Pseudallescheria boydii TIMM1338. Each denatured DNA $(1 \mu \mathrm{l})$ was blotted on a nylon membrane filter and exposed to UV fixation. Prehybridisation was performed at $50^{\circ} \mathrm{C}$ for $1 \mathrm{~h}$ with hybridisation buffer (10 mM Tris- $\mathrm{HCl}, \mathrm{pH}$ 7.6, formamide 50\%, Denhart's solution, dextran sulphate $10 \%, 600 \mathrm{mM} \mathrm{NaCl}, \mathrm{SDS}$ $0.25 \%$ and $1 \mathrm{~mm}$ EDTA, pH 8.0). Methods for hybridisation and detection of the hybridisation signals were the same as those for ISH.

\section{Results}

\section{Specificity of probes}

The specificity of the alp-568 probe was tested by dotblot and Southern blot hybridisation with genomic DNA from each fungal strain. As shown in Fig. 1, no cross-hybridisation was detected between any fungal species, including several Aspergillus and Penicillium spp. The positive signal was observed only with $A$. fumigatus genomic DNA.

\section{ISH for A. fumigatus ALP gene}

The three probes for $A$. fumigatus ALP gene, i.e., alp568 (568 bp), alp-333 (333 bp) and alp-154 (154 bp), and the non-fungal probe for Mycoplasma pneumoniae ITS (646 bp) were labelled by PCR with DIG-11-dUTP.

In ISH with the alp-568 probe for A. fumigatus ALP gene, strong positive staining was observed within fungal organisms present in neutralised formalin-fixed paraffin-embedded tissues of the lung and kidney from rats and mice, respectively, infected with $A$. fumigatus (Figs. $2 b$ and $3 a$ ). The signal was visible within hyphal forms of the filamentous fungus. In all specimens tested the majority of organisms invading the tissues were stained, except those within the centre of aspergillomas. ISH was performed with three different concentrations of the alp-568 probe $(2 \%, 5 \%$ and $10 \%)$ in the hybridisation mixture. ISH with the $5 \%$ probe concentration gave the most vivid signals from hyphae in the tissue. ISH with the $10 \%$ concentration caused a high background signal. Substantial signals were also observed in tissues from A. flavus-infected mice (Fig.

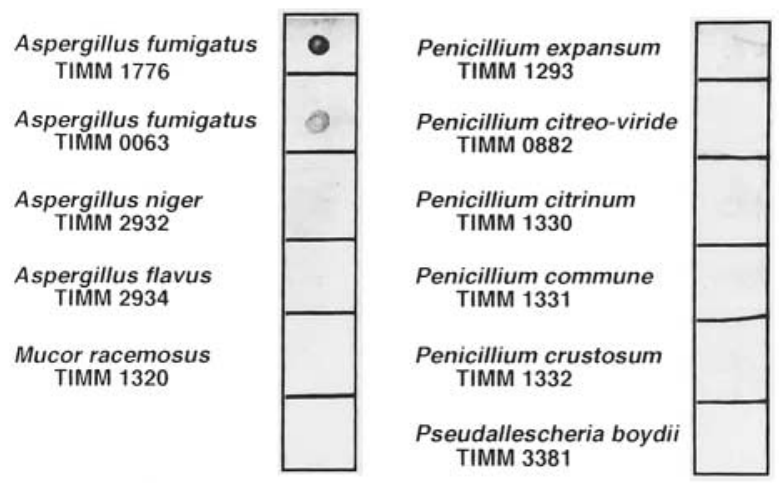

Fig. 1. The specificity of the alp-568 probe tested by dotblot and Southern blot hybridisation with genomic DNA from each fungal strain: the positive signal was observed only with $A$. fumigatus genomic DNA and not with other fungal species tested. 
$3 d)$. In tissues from A. niger-infected mice, signals were seen on only part of the hyphae (Fig. 3e). There was virtually no signal in renal tissues from mice infected with T. asahi (Fig. 3f).

With the alp-333 probe at concentrations from 10 to $20 \%$, equally strong signals were observed in both $A$. fumigatus-infected and A. flavus-infected tissues, although their intensity appeared weaker than that obtained with the alp-568 probe (Fig. $4 a, b)$, and there was no visible signal in tissues from $A$. niger-infected animals. With the alp-154 probe, even though it was used at a concentration as high as $20 \%$, no signal was observed in any of these tissues (Fig. 4c).

No signal was observed in pulmonary tissues from $A$. fumigatus-infected rats with the unlabelled alp-568 probe or in comparable tissues from uninfected animals with the labelled alp-568 probe. When the labelled and unlabelled probe were mixed in various proportions, signals became weaker with increasing concentrations of the latter. With the M. pneumoniae ITS probe at a concentration of $20 \%$, pulmonary tissues from A. fumigatus-infected rat gave no positive reaction.

\section{Discussion}

The alp-568 probe was highly specific for $A$. fumigatus when tested by dot-blot hybridisation. This can be explained by relatively low homologies in $568 \mathrm{bp}$ of ALP genes among Aspergillus species (53.3\% between A. fumigatus and $A$. flavus, and $45 \%$ between $A$. fumigatus and $A$. niger). However, this probe gave a positive reaction with the related Aspergillus spp., A. flavus and $A$. niger, when tested on tissues from animals infected with these fungi by ISH under the same experimental conditions in terms of temperature. Hybridisation in the tissues seems to have a lower stringency than hybridisation on the membrane, because of the existence of cross-linked proteins or other proteins which could inhibit the formation of hybrids. It is possible that the interaction of the target gene with protein to form a DNA-protein cross-linked structure [15] in formalin-fixed tissues facilitates the cross-reaction. According to FASTA, the ALP gene of $A$. fumigatus is homologous to that of related species in the order A. oryzae, A. flavus, A. nidulans and A. niger. This may explain, partly at least, why the crossreactivity with $A$. flavus was stronger than that with $A$. niger. Consequently, the alp-568 probe appears to have sufficient specificity to distinguish $A$. fumigatus and $A$. flavus from other Aspergillus spp. or from nonAspergillus fungi.

A. fumigatus hyphae in the invaded tissues reacted with the alp-568 probe and, to a lesser extent, the alp-333 probe, but did not react with the alp-154 probe, which was an internal probe of the alp-333 probe. In ISH systems thus far developed in which some high copy number nucleic acid sequences such as rRNA are used as the target, oligoprobes (20-40 mer) work well. As ALP is a single copy gene located on the chromosome [16], larger amounts of DIG-11-dUTP might be required for take up into long probes sufficient for detection by ISH techniques with a DIG-labelled probe.

ISH techniques have been used successfully to detect and diagnose several bacterial, viral and protozoan pathogens present not only in invaded tissues, but also in some fluid specimens such as blood [5] and vaginal secretions [7]. In contrast, only a few reports deal with ISH for the detection of pathogenic fungi. M ontone and Litzky $[9,10]$ reported an ISH technique for the detection of Aspergillus spp. and Pneumocystis carinii in infected tissues. ISH detection of $\mathrm{Pn}$. carinii was also studied by Hayashi et al. [11]. They selected $5 \mathrm{~S}$ or $18 \mathrm{~S}$ rRNA sequences as an optimal target for ISH. Generally, as RNA exists in a high copy number [11] in individual cells, rRNA could be an optimal target. However, RNA is biochemically unstable with molecules highly susceptible to RNAase, which is difficult to remove from tissue specimens. This usually leads to degradation of cellular RNA and, in turn, deterioration of the specimen. In this respect, ISH techniques with DNA as the target appear advantageous because of their biochemical and physicochemical stability. Fey et al. [17] reported that DNA which had been prepared from bone marrow 13 years previously was analysed successfully by Southern hybridisation techniques. Thus the present study chose DNA rather than RNA as the target to develop ISH techniques to detect fungi which are applicable to formalin-fixed, paraffinembedded specimens.

Several other molecular biological techniques, such as $P C R$, restriction endonuclease analysis (REA) and random amplified polymorphic DNA (RAPD) are also expected to be useful techniques for rapid diagnosis of deep mycosis. Numerous PCR techniques to detect fungus-specific DNA in blood and other clinical specimens have been reported. However, time is required to extract a pathogen's DNA from a specimen and contamination with other micro-organisms can be a problem. With ISH it is not necessary to extract DNA from specimens and contamination can be recognised easily. REA, RAPD, karyotyping and DNA fingerprinting [18] have the disadvantage that it is difficult to analyse the results. Analysis of the results of ISH is quite simple. ISH is more rapid than conventional culture and can detect non-viable organisms. The key feature distinguishing ISH from the other molecular biological methodologies such as filter hybridisation or PCR is that the sample is detected directly in the intact cell rather than by extracting DNA from the cell before testing. Immunohistochemistry is also a useful method that can detect and localise pathogens, but there are still some problems: production of antibody takes a long time and much effort; it is difficult to make antibody of uniform quality; and the problem of cross-reactivity is 

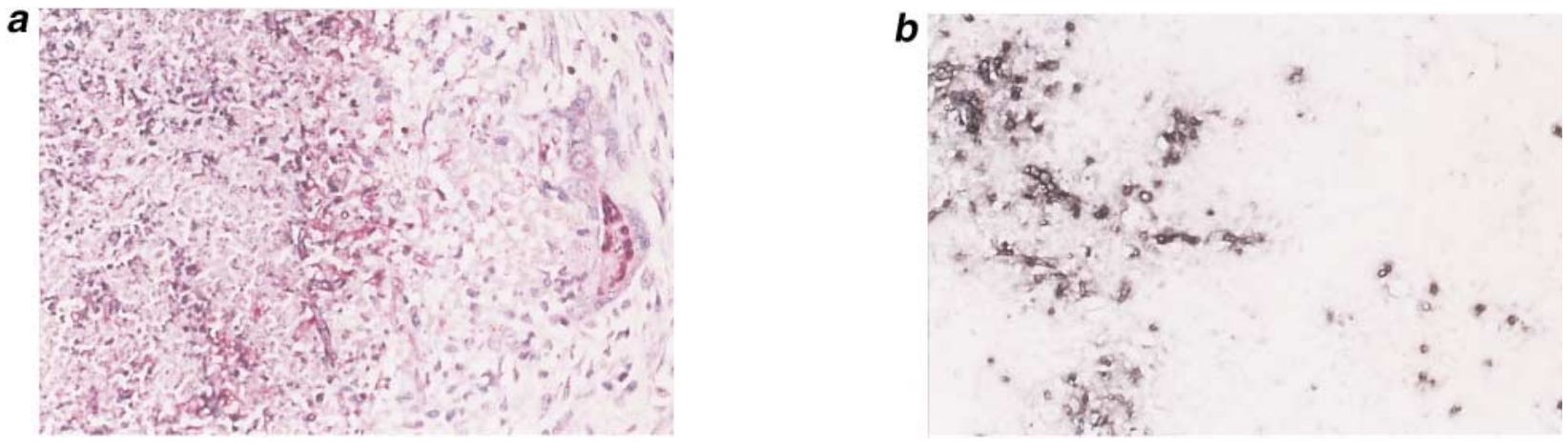

Fig. 2. Micrographs of pulmonary tissue from a rat infected with A. fumigatus. (a) ISH with the alp-568 probe shows A. fumigatus $(\times 100)$. (b) PAS staining shows $A$. fumigatus in the same area $(\times 100)$.
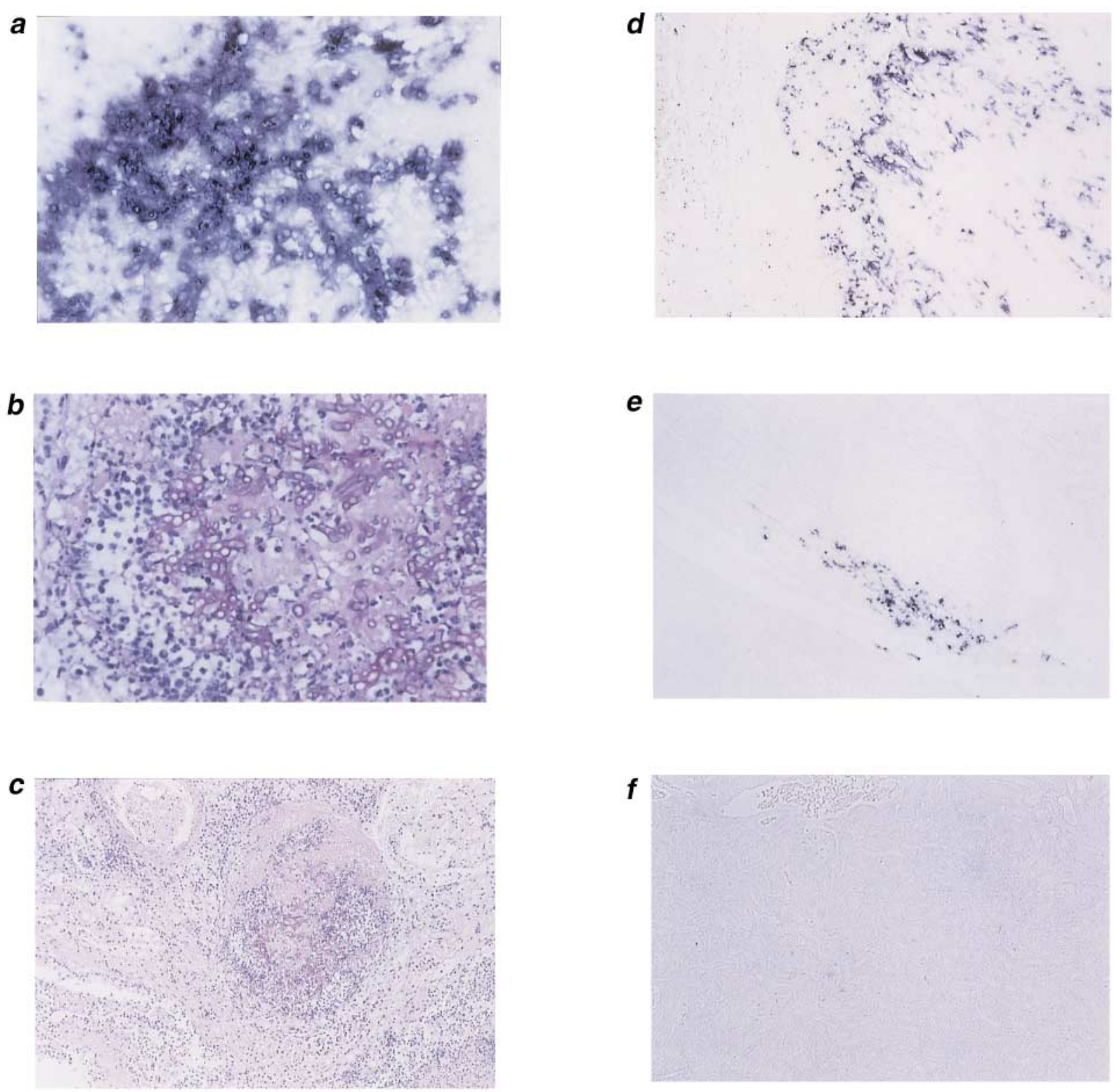

Fig. 3. Micrographs of renal tissue from mice infected with $A$. fumigatus $(a, b, c)$, A. flavus (d), A. niger (e), or T. asahi (f). (a) ISH with the alp-568 probe shows A. fumigatus with strong intensity $(\times 132)$. (b) PAS staining shows A. fumigatus in the same area $(\times 132)$ and $(c)(\times 33)$. (d) ISH with the alp-568 probe shows $A$. flavus in renal tissue $(\times 33)$. (e) In renal tissue from $A$. niger-infected mice, signals were seen on only part of the hyphae $(\times 33)$. $(f)$ There was virtually no signal in renal tissues from mice infected with $T$. asahi $(\times 33)$. 

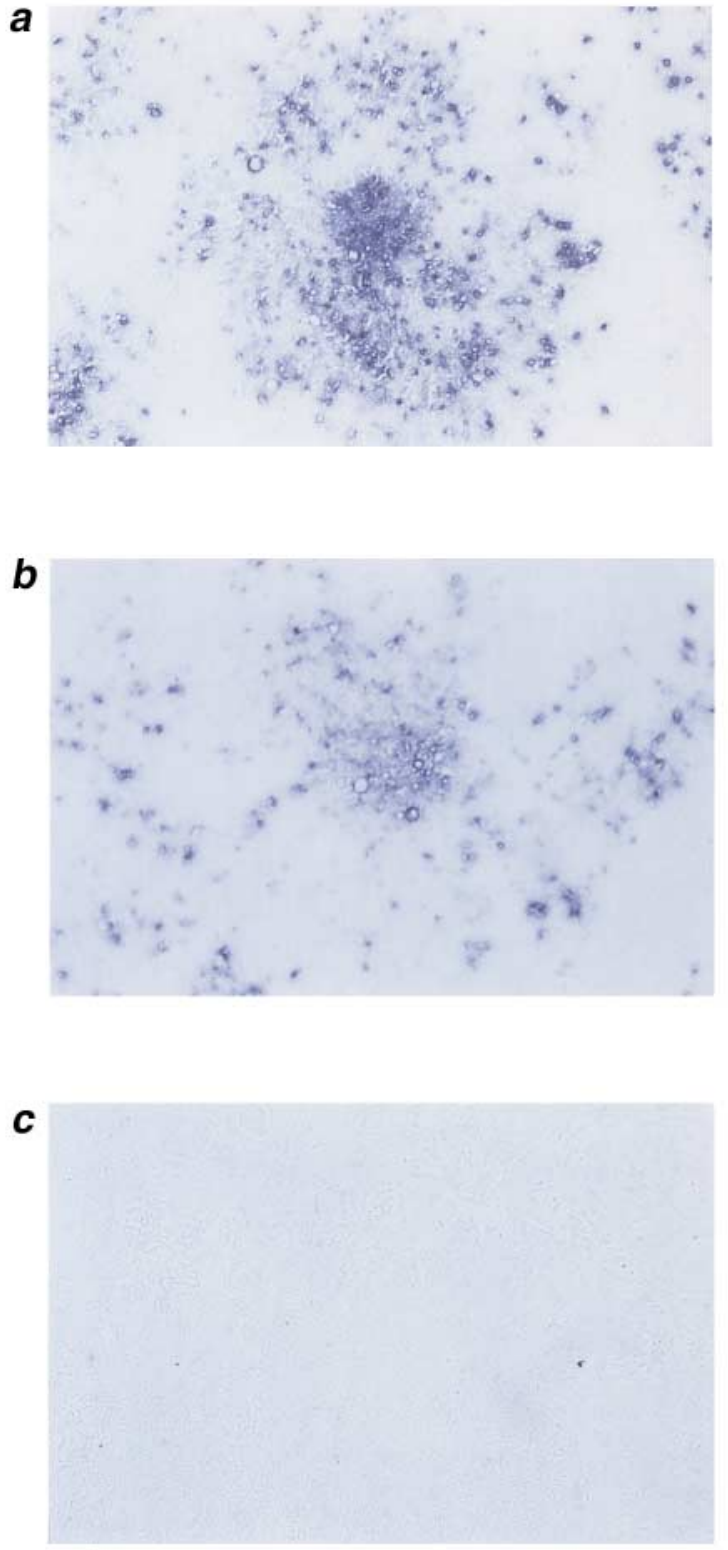

Fig. 4. Influence of the probe length on the intensity of the ISH signals. (a) ISH with alp-568 (568 bp) probe shows strong positive results and clearly shows the hyphae of $A$. fumigatus in the pulmonary tissue from a rat infected with that organism; (b) in ISH with the alp333 (333 bp) probe the intensity appears weaker; (c) ISH with the alp-154 (154 bp) probe shows no signal $(\times 66)$.

still difficult to solve [19]. In contrast, high quality probes can be prepared within 1 working day by the PCR system and high quality probe is easily obtained.

In summary, A. fumigatus and A. flavus can be detected specifically in tissues by ISH. Further studies on the clinical application of this method are under way.

We thank Drs Kazutoshi Shibuya and Shiro Naoe (Department of Pathology, Toho University Ohashi Hospital) for helpful discussions and the preparation of tissues.

\section{References}

1. Perfect JR, Schell WA, Rinaldi MG. Uncommon invasive fungal pathogens in the acquired immunodeficiency syndrome. J Med Vet Mycol 1993; 31: 175-179.

2. Kappe R, Schulze-berge A. A new cause for false-positive results with the Pastorex Aspergillus antigen latex agglutination test. J Clin Mircobiol 1993; 31: 2489-2490.

3. Siemann M, Koch-Dorfler M, Gaude M. False-positive results in premature infants with the Platelia Aspergillus sandwich enzyme-linked immunosorbent assay. Mycoses 1998; 41: 373- 377.

4. Makimura K, Murayama SY, Yamaguchi $H$. Detection of a wide range of medically important fungi by the polymerase chain reaction. J Med Microbiol 1994; 40: 358-364.

5. Matsuhisa A, Saito $Y$, Sakamoto $Y$ et al. Detection of bacteria in phagocyte-smears from septicemia-suspected blood by in situ hybridization using biotinylated probes. Microbiol Immunol 1994; 38: 511-517.

6. Beutler AM, Schumacher HR, Whittum-Hudson JA, Salameh WA, Hudson AP. Case report: In situ hybridization for detection of inapparent infection with Chlamydia trachomatis in synovial tissue of a patient with Reiter's syndrome. Am J Med Sci 1995; 310: 206-213.

7. Muresu R, Rubino S, Rizzu P, Baldini A, Colomob $M$ Cappuccielli P. A new method for identification of Trichomonas vaginalis by fluorescent DNA in situ hybridization. J Clin Microbiol 1994; 32: 1018-1022.

8. Nuovo GJ, Gallery F, M acConnell P, B raun A. In situ detection of polymerase chain reaction-amplified HIV-1 nucleic acids and tumor necrosis factor-alpha RNA in the central nervous system. Am J Pathol 1994; 144: 659-666.

9. Montone $K T$. In situ hybridization for ribosomal RNA sequences: a rapid sensitive method for diagnosis of infectious pathogens in anatomic pathology substrates. Acta Histochem Cytochem 1994; 27: 601-606.

10. Montone KT, Litzky LA. Rapid method for detection of Aspergillus $5 S$ ribosomal RNA using a genus-specific oligonucleotide probe. Am J Clin Pathol 1995; 103: 48-51.

11. Hayashi $Y$, Watanabe J, Nakata K, Fukayama M, Ikeda H. A novel diagnostic method of Pneumocystis carinii. In situ hybridization of ribosomal ribonucleic acid with biotinylated oligonucleotide probes. Lab Invest 1990; 63: 576-580.

12. Kolattukudy PE, Lee JD, Rogers LM et al. Evidence for possible involvement of an elastolytic serine protease in aspergillosis. Infect Immun 1993; 61: 2357-2368.

13. Harasawa R, M izusawa H, Nozawa K, Nakagawa T, A sada K, $K$ ato I. Detection and tentative identification of dominant mycoplasma species in cell cultures by restriction analysis of the 16S-23S rRNA intergenic spacer regions. Res Microbiol 1993; 144: 489- 493.

14. Shibuya K, Ando T, Wakayama M, Takaoka M, Uchida K, Naoe S. Pathological spectrum of invasive pulmonary aspergillosis - study of pulmonary lesions of 54 autopsies and the relationship between neutrophilic response and histologic features of lesions in experimental aspergillosis. Jpn J Med Mycol 1997; 38: 175-181.

15. Nuovo GJ. In: PCR in situ hybridization: protocols and applications, 3rd edn. Philadelphia, Lippincott-Raven. 1997: 123-192.

16. Tang CM, Cohen J, Holden DW. An Aspergillus fumigatus alkaline protease mutant constructed by gene disruption is deficient in extracellular elastase activity. Mol Microbiol 1992; 6: 1663-1671.

17. Fey MF, Pilkingon SP, Summers C, Wainscoat JS. Molecular diagnosis of haematological disorders using DNA from stored bone marrow slides. $\mathrm{Br}$ J Haematol 1987; 67: 489-492.

18. Girardin H, Latge J-P, Srikantha T, Morrow B, Soll DR. Development of DNA probes for fingerprinting Aspergillus fumigatus. J Clin Microbiol 1993; 31: 1547-1554.

19. Kaufman $L$, Standard $P G$, Jalbert $M, K$ raft DE. Immunohistologic identification of Aspergillus spp. and other hyaline fungi by using polyclonal fluorescent antibodies. J Clin Microbiol 1997; 35: 2206-2209. 